CVIA

EDITORIAL

pISSN 2508-707X / elSSN 2508-7088 https://doi.org/10.22468/cvia.2019.00080 CVIA 2019;3(2):32-32

Accepted: April 29, 2019

Corresponding author

Sang II Choi, MD, PhD

Department of Radiology,

Seoul National University

Bundang Hospital, 82 gumi-ro,

173 Bundang-gu, Seongnam 13620,

Korea

Tel: 82-31-787-7611

Fax: 82-31-787-4011

E-mail: drsic@hanamil.net,

sichoi@snu.ac.kr

\section{Cardiovascular Imaging Asia: Quantum Jump in the Asian Society of Cardiovascular Imaging}

\author{
Sang II Choi \\ Department of Radiology, Seoul National University Bundang Hospital, Seongnam, Korea
}

\begin{abstract}
Cardiovascular Imaging Asia is the official journal of the Asian Society of Cardiovascular Imaging (ASCI) from 2017. The ASCI has published scientific papers to produce and propagate the scientific activities of the society members in collaboration with International Journal of Cardiovascular Imaging, which is the official journal of the North American Society for Cardiovascular Imaging, as an ASCI special issue since 2009. I convince that the CVIA will be a leading journal in the field of cardiovascular imaging in Asia and will encourage the members of the $\mathrm{ASCl}$ to propagate scientific activities.
\end{abstract}

Key words Heart . Imaging · Society · Journal.
It is my great honor to be the next Editor-in-Chief of Cardiovascular Imaging Asia (CVIA), the official journal of the Asian Society of Cardiovascular Imaging (ASCI) from this year. The ASCI has published scientific papers to produce and propagate the scientific activities of the society members in collaboration with International Journal of Cardiovascular Imaging, which is the official journal of the North American Society for Cardiovascular Imaging, as an ASCI special issue since 2009.

I would like to extend my deepest gratitude to Professor Dr. Yeon Hyeon Choe (2009-2013), who was the past President of the ASCI, the first guest Editor-in-Chief, and an adjunct editor of the International Journal of Cardiovascular Imaging. I also appreciate the efforts of Dr. Tae Hoon Kim, my immediate predecessor (2014-2018), who also served as the guest Editors-inChief of the special issues and 1st Editor-in-Chief of CVIA in making this journal visible $[1,2]$. His contributions to the evolution of cardiovascular imaging in Asia have been enormous.
I am pleased to introduce Dr. Kakuya Kitagawa (Mie University Hospital, Japan), as a new Deputy Editor who has many publications and presented papers at major society meeting as well as the congress meeting of ASCI. I am very delighted that he has accepted a position as Deputy Editor for this journal. In addition, I would like to show my special thanks to article authors, editors, and reviewers.

Finally, I convince that the CVIA will be a leading journal in the field of cardiovascular imaging and will encourage the members of the ASCI to propagate scientific activities.

\section{REFERENCES}

1. Choe YH. Launching of a new cardiovascular imaging society: the Asian Society of Cardiovascular Imaging. Int J Cardiovasc Imaging 2009;25 Suppl 1:3-7.

2. Kim TH. Cardiovascular Imaging Asia: A New Era in the Asian Society of Cardiovascular Imaging. Cardiovasc Imaging Asia 2017;1:2-3. 